\title{
TOWARD A SERRESIAN RECONCEPTUALIZATION OF KANTIAN RESPECT Bryan Lueck
}

For Immanuel Kant the most basic phenomenon of moral life, the categorical imperative, is ineluctably bound up with an essential difference between the sensible and the intelligible, across which practical subjectivity is constituted. More specifically, the moral imperative can be experienced only by a finite rational subject whose faculty of desire is divided into lower and higher stems. The lower faculty of desire is determined pathologically, i.e., by the feelings of pleasure and pain, and thus concerns the sensible side of practical subjectivity. ${ }^{1}$ The higher faculty of desire, on the other hand, is determined exclusively by the pure moral law, and thus concerns the intelligible side of practical subjectivity. For Kant, "all imperatives are expressed through an ought and thereby indicate the relation of an objective law of reason to a will which in its subjective constitution is not necessarily determined by that law (a necessitation)." ${ }^{2}$ For a being whose will is determined exclusively by the moral law, i.e., without any contribution whatever from sensibility, the element of necessitation or of command that is essential to the experience of the imperative would be entirely out of place. Such a being would act in accordance with the moral law as certainly as natural objects act in accordance with the laws of nature, so that a command to do so would be superfluous. On the other hand, a being whose will is determined exclusively by the feelings of pleasure and pain would be unable even to conceive of the objective law of reason to which it would be commanded to submit itself. In sum, only a being whose practical subjectivity is extended across this essential difference could feel an imperative weighing on its 
sensibility and experience it as referring beyond its own inclinations to the objective and impersonal moral law.

It is enormously important within the context of Kantian moral philosophy to maintain the sharp distinction between the two sides of our practical nature. This is because our acts, in order to acquire that kind of worth that is uniquely moral, must be governed entirely by the intelligibly determined higher faculty of desire, and not at all by the sensibly determined lower faculty. The moral law, for Kant, is characterized most essentially as unconditional and as objective. The lower faculty of desire, which requires as its incentive an object that promises the subject some degree of pleasure, can give rise at best to hypothetical imperatives, which are conditional and subjective. Principles arising from the lower faculty of desire are conditional because they depend on contingent circumstances for their imperative force. I would, for example, feel compelled to get myself a cup of coffee only on the condition that I actually enjoyed coffee, and moreover, that I would enjoy a cup of coffee at that particular moment. Principles of this kind are subjective in that the pleasure that serves as their incentive refers only to particular subjects, and not to the object. That coffee would be pleasurable to me at that moment, for example, is a fact about me, and not about coffee. The kind of compulsion that Kant thinks of as uniquely moral, on the other hand, is experienced as an unconditional command, indifferent or even opposed to our particular inclinations. I respond to the command of the moral imperative not as the particular person I am, with my particular likes and dislikes, but rather as a rational subject, the same as any other. I recognize, for example, that I must not defraud the other party to a financial transaction, even though doing so would be to my advantage. This prohibition has nothing to do with 
me in particular or with the circumstances of this particular transaction. My being destitute, for example, and the other party's being fabulously wealthy do not affect the moral command in the least. Rather, I recognize in this prohibition an impersonal duty that applies universally and unconditionally. This experience I have of a command that makes claims against my sensuously determined inclinations and that makes the same claims indifferently against all rational subjects reveals at once the generic difference between the higher and lower faculties of desire and the moral necessity of subordinating the latter rigorously to the former.

In certain passages, Kant seems to argue that moral worth depends on our eliminating all traces of sensible motivation from our willing. He writes, for example, in the Critique of Practical Reason, that "what is essential in the moral worth of actions is that the moral law should directly determine the will."3 And again, "reason determines the will in a practical law directly, not through an intervening feeling of pleasure or displeasure, even if this pleasure is taken in the law itself. Only because, as pure reason, it can be practical is it possible for it to give law." ${ }^{, 4}$ For this to happen, we must reject all of the "sensuous impulses" that attempt to cooperate in the determination of our finite wills. ${ }^{5}$ Thus, if I take measures to benefit my fellow human beings because of the sympathetic feelings I have toward them, my acts will have "no true moral worth." The very same act will have moral worth, however, if it is done for no other reason than that the moral law commands it. Examples like this contribute to the perception of Kantian ethics as rigidly formalistic and as demanding a humanly impossible renunciation of our natural and obviously morally relevant feelings. 
Although this example and others like it are Kant's own, they do present an unduly one-sided image of his broader moral philosophy. Although the general tendency of Kant's ethics is certainly toward minimizing the role of feeling, it remains impossible for him to eliminate that role entirely. More specifically, feeling returns at the very heart of Kant's ethics in the guise of respect. Although Kant had written that moral worth depends on the will's having been determined directly by the moral law, without the intervention of sensibility, his own system in fact demands a more nuanced account. Strictly speaking, the law can never motivate our wills immediately; it can be effective in determining the will only through our consciousness of it. ${ }^{7}$ And for finite rational beings like us, consciousness of the law is inseparable from the feeling of respect. Respect for Kant is experienced as a kind of pain that accompanies the thwarting of our inclinations by the moral law. I might, for example, be inclined to tell a lie in order to advance my own interests. This inclination, and indeed all of my inclinations, reflects a kind of selfish interest in my own happiness that is grounded in the lower, non-moral faculty of desire. The moral law, in opposing this selfish orientation toward happiness, weighs painfully on my sensibility and thereby reveals to me the moral law as a higher standard to which I must refer in my practical deliberation. The law acts as a counterforce to my inclination to benefit myself through the lie, but it does so only by means of the painful feeling of respect. Without this feeling, I would never become aware of a practical orientation other than the one furnished by my natural desire for happiness. Kant, then, states the relation of feeling to morality more adequately when he writes that respect is "the sole and undoubted moral incentive." 
It would be a serious mistake to think of respect simply as one feeling among others. In fact, with respect we encounter a phenomenon that has no place marked out for it within Kant's system of metaphysics. Kant himself recognizes the strangeness of respect, describing it as "a singular feeling, which cannot be compared with any pathological feeling." ${ }^{\prime 9}$ While the ordinary, pathological feelings help us to orient ourselves in the sensibly given world by disclosing objects as things to be pursued or avoided, the singular feeling of respect refers us immediately to the intelligible world of the moral law. Indeed, the feeling of respect never has mere things for its objects. We may fear or enjoy things, or even admire them, but to say that we respect them would be to overlook what is uniquely moral in our practical relation to the world. In the feeling of respect I find myself exposed to others as moral persons, as free, legislating subjects like myself whose supersensible dignity I must never violate and to whom I must never relate simply in accordance with my own self-interested inclinations. ${ }^{10}$ In respect, then, the sensible and the intelligible that Kant generally takes such great pains to keep separate are given immediately together in a single phenomenon: "Respect for the law, which in its subjective aspect is called moral feeling, is identical with consciousness of one's duty." 11

We might say, stepping back somewhat from Kant's own formulations, that the whole of morality is gathered together into a kind of dense point in the singular feeling of respect. It is respect that discloses most originarily the division between the sensible and the intelligible across which practical subjectivity is necessarily extended. It not only establishes the generic difference between these two worlds, but it also holds them together in a practically necessitated, determinate relation. More specifically, in respect I 
feel a kind of pain that opens me immediately to the intelligible law, to which I am commanded to subordinate my sensibly determined lower faculty of desire. Although respect first discloses the difference between the sensible and the intelligible, it can be conceived itself only as exceeding that difference. Respect is indeed a feeling, but it is, so to speak, an intelligible feeling, "the only one which we can know completely a priori and the necessity of which we can discern." ${ }^{, 12}$ In sum, every phenomenon that Kant thinks of as uniquely moral is gathered together and has its origin in respect. As Kant himself writes, "respect for the law is not the incentive to morality; it is morality itself. . , 13

By presenting respect in this way — as opening up a practical world characterized by the sharp division between sensibility and the intelligible law, and as itself exceeding the terms of that division - I hope to bring it explicitly within the purview of the work of Michel Serres, and especially of the phenomenon that he has articulated variously as the parasite, noise, and the excluded/included third. More specifically, I shall attempt using these Serresian concepts to redescribe the feeling of respect in a way that does not presuppose the metaphysical schema that it both founds and exceeds. In fundamentally redescribing this most originary moral phenomenon, I hope to call into question the purity and the intelligibility of the moral law that it reveals and to disclose a more complex and ambiguous kind of sense right at the heart of our moral opening out onto the world.

The aspect of Serres's work that I wish to present as especially relevant to a redescription of Kantian respect is influenced to a great degree by information theory. Broadly speaking, the goal of information theory is to understand the process by which 
messages, encoded and transmitted across channels of communication, are decoded and received at their points of destination. More specifically, the first researchers in information theory sought to discover the means by which messages could be transmitted within systems of telecommunication with a minimum of loss. This loss can be attributed to the properties of the channels across which messages are sent. So, for example, messages sent out over the radio are often distorted by static, while televised messages are often distorted by "snow." Or, at a much simpler level, the message that I send in a handwritten note is distorted by the peculiarities of my own handwriting. Even the message I send in a direct, face-to-face conversation can be distorted by my mispronunciations or by my regional dialect. ${ }^{14}$ The general name for all of these obstacles to successful, transparent communication is noise. Among the most important tasks of information theory, then, is to model and to produce systems for the transmission of messages that eliminate noise to the greatest degree possible.

In the essay "Platonic Dialogue" and elsewhere, Serres attempts to show this noise-eliminating project at work in the founding texts of western philosophy and in the broader intellectual tradition to which they help to give rise. He argues that we must understand the interlocutors of the Platonic dialogues not primarily as adversaries, but rather as allies doing battle together against the ever-present threat of noise. In the dialogues, as in all communication, noise functions as the third that must be excluded for the sake of a truth that the interlocutors can agree to. ${ }^{15}$ So, for example, in order to understand the bed that truly is, Glaucon must learn to turn his attention away from particular beds with their particular qualities. The particularities of different beds - their particular sizes, shapes, colors, etc.- - function as noise, as obstacles to the comprehension 
of the ideal, transparently intelligible bed. One can also understand Descartes' project in the Meditations as an attempt to rebuild the system of knowledge in a way that eliminates all of the noise of doubt. In the cogito, Descartes discovers a new foundation where communication is maximally transparent, where the thought of the I and the certainty of its existence are connected in a way that excludes all possibility of noise. ${ }^{16}$ Finally, it would not be very difficult to see in Kant an attempt to eliminate the noise of pathological feeling and of empirical experience from the system of morality. Just as in Plato particular beds obscure the transparent ideality of the one true bed, so for Kant "everything that is empirical is, as a contribution toward the principle of morality, not only entirely unfit for it, but even highly disadvantageous to the purity of morals themselves. ..."17 In the third formula of the categorical imperative, according to which we must exercise our wills as legislative members of a purely ideal kingdom of ends, we can see Kant presenting the task of creating of a moral community maximally purged of noise.

As we have seen, Kant tends to think of this noise — of the role of feeling in our practical relation to the world - as a limitation and as a mark of our finitude. If our wills were holy, as they would be if they were not also influenced by sensuous motives, then we would never experience the least resistance to the pure moral law. For finite rational beings like us, however, the best that can be hoped for is continuous, unending progress toward the ideally pure will. ${ }^{18}$ We can, in other words, never hope to eliminate the noise entirely from our moral worlds, but we must never stop working to reduce it to the minimum possible. This way of presenting our moral task suggests that the purity of the 
law is the natural condition and that the noise that obscures it happens as an unfortunate aberration.

One of the most important concerns in Serres's work is to challenge this prejudice in favor of the primacy of law, order, and intelligibility over the disorder of noise. According to Serres, order is not the norm, but rather a fleeting and transient exception to the rule of noise. "Order is never more than an island or an archipelago. In the midst of the multiple, one finds universe-isles." ${ }^{.19}$ This idea is developed in detail in The Parasite, where Serres presents noise as radically ambiguous, at once the force that ceaselessly disrupts the smooth functioning of the system and the very origin of that system. It is at once a third that must be excluded and a first term that can never be excluded, and indeed, must not be excluded. The argument of the book calls upon the polysemy of the French parasite. First, a parasite is a person who eats at the table of another, paying for his meal with flattering or witty language. Second, and closely related, a parasite is an organism that lives in and at the expense of another organism of a different species. Finally, parasite is another name for the noise within a system of communication that disrupts the messages transmitted across it. These senses of the word have an important feature in common: in all three senses, the parasite interrupts and undermines the smooth functioning of a system by introducing a disequilibrium. In the first case, the parasite introduces an unequal exchange of words for things. The parasite extracts real value from the system (the food that sustains him), but gives nothing of comparable value in return. In the second case, the parasite interrupts the flow of nutrients that sustain the host's organism, while apparently giving nothing at all in return. In the third case, the 
parasite detracts from the message as it is transmitted across channels of communication and gives in return only meaningless noise.

In all these cases, the parasite "presents itself in a negative guise: it is viewed as a malfunction, an error, or a noise within a given system. Its appearance elicits a strategy of exclusion. In order for a system to function to perfection, it would seem necessary to eliminate all parasites. ${ }^{20}$ To adopt this perspective toward the parasite is to grant the system and its order an epistemological, or even ontological, primacy. From the perspective of the system, the existence of parasites gives rise to an imperative to work. To work is simply to struggle against the noise. ${ }^{21}$ Thermodynamics and information theory both tell us that, left to themselves, systems tend toward disorder. Without work, "the stables would fill up with manure, the fox would eat the chickens, and the phylloxera would cross the seas to dry out the vine leaves." ${ }^{22}$ We can recognize in Kant's moral philosophy an imperative to work conceived in this way. To act morally is to take the side of the system, which is to take sides explicitly against the noise. Moral worth for Kant does not come simply from acting in accordance with the law; here lies the whole difference between morality and mere legality. If I benefit a friend because of the warm feelings I have toward him, my action has no specifically moral worth because it required no moral work. I have not struggled against the noise of feeling at all, but have rather made use of it and thereby made a place for it within my practical life. Morality for Kant thus presupposes the primacy of pure practical reason, which must be preserved against the noise that would disrupt it. But it also presupposes the noise as a constant presence and as inseparable from the system. "There is no system without parasites. This constant is a law." ${ }^{23}$ Without the noise, in short, there is no morality. 
We can see from this example that the disequilibrium introduced by the parasite is not simply an impediment to the functioning of the system. We can never hope, even in principle, to eliminate all of the noise from the system because noise is in fact integral to its functioning. Noise is the background against which the system emerges. "Rigorously speaking, there is never silence. The white noise is always there... Systems work because they do not work. Nonfunctioning remains essential for functioning." ${ }^{24}$ The excluded third is in fact a first that is included always already.

Serres demonstrates this point in The Parasite by means of careful and inventive readings of the popular fables of Jean de la Fontaine. In his first fable, "The Grasshopper and the Ant," La Fontaine presents the perspective of the system and its valorization of work. The fable tells of a grasshopper who had run out of food and who sang a song for the ant, hoping to convince him to share some of his surplus. The grasshopper hoped to initiate the classically parasitic and unequal exchange of sound for substance. The ant, as representative of the system and of work, contemptuously refused. The society of ants serves as a model for rational order: "it works by chasing out disorder. It constituted order, classifying its seeds, flies, worms; chasing away the singers and dancers." ${ }^{25}$ The fable shows that the maintenance of the rational order is based on an exclusion, on carefully guarding the frontier between information and noise. What this first fable does not mention, and what the later fables will emphasize, is that the work necessary to maintain the rational order itself makes noise. The pure rationality represented by the anthill requires the possibility of work without loss. In fact, though, the ants necessarily produce parasites in the very act of chasing them out. And the more the ants struggle against the parasites, the more parasites they will produce. The moral of this expanded 
version of the fable is simply this: it is better to include your parasites, to accept the unequal exchange that they propose. The alternative is to continuously raise the stakes, to expend more and more energy, and thus to make more and more noise, simply to maintain a simplistic and unattainable purity. "Pure reason is inflation. Inaccessible purity raises its prices." ${ }^{26}$

La Fontaine demonstrates this point explicitly in "The Gardener and the Squire." The gardener of the story possesses a modest garden, which he encloses carefully with a hedge. The hedge, though, must have had a small hole in it, for one day the gardener discovers a hare nibbling at his vegetables. The hare, of course, is the parasite who institutes a disequilibrium: he takes for himself the products of the gardener's work and gives nothing in return. As such, the hare appears to the gardener as a third that must be excluded at all costs. Unable to do so by himself, the gardener calls to his aid the local sovereign, who vows to take care of the problem for him. The gardener has thus called in one parasite to rid himself of another. Very quickly the squire and his retinue begin consuming all of the gardener's food and making claims on his daughter. As the squire's hunters chase the hare out of the garden, their horses tear a hole in the hedge far wider than the one that originally allowed the hare to pass through. Clearly the gardener would have done better to learn to live with his parasite and to accept the disequilibrium that characterizes the parasitic relation. Our gardens are never closed off completely from the rest of the world. There is always already a hole in the hedge and the hare has always already passed through. We are, in other words, always already exposed and in relation to a world outside our own system of order. And as we learn from information theory, there can be no relation without noise in the channels. To try to eliminate the parasites, 
then, and to try thereby to return to a fictitious original purity, is to introduce another parasite that is a much greater threat to the system than the first. For Serres, "tolerance begins here, and maybe morality as well., ${ }^{27}$

These examples show that rational systems necessarily make noise. The rational ants might contemptuously refuse the unequal exchange offered by the grasshoppers, but that will not make the grasshoppers stop chirping. The ants will be able to keep out the noise of the grasshoppers only by producing a greater noise of their own. But it is equally the case that noise makes the system. The set of interferences, interceptions, losses, and holes is not so much a kind of cancerous growth within the system as it is just the system itself. ${ }^{28}$ The disequilibrium that the parasite introduces into the system-the exchange of food for a song, of the garden vegetables for nothing at all — constitutes the system itself. "The difference is part of the thing itself, and perhaps it even produces the thing. Maybe the radical origin of things is really that difference, even though classical rationalism damned it to hell. In the beginning was the noise. ${ }^{29}$

Serres offers a particularly powerful and intuitive demonstration of the priority of noise in Angels: A Modern Myth. ${ }^{30}$ An angel, as its etymology suggests, is a messenger. If we try to understand the role of angels using the most basic model of information theory, where an information source sends a message to a point of destination by means of a channel of communication, then we would say that the angel serves as the middle term, the channel that mediates between source and destination. In this scenario, the information source is God and the destination is humanity. While God is spiritual and humanity is fleshly, the angel is both and neither. It is this lack of self-identity, this difference from self, that allows the angel to mediate the relation. 
But we know that there is no relation without its parasites. In this case, the angel cannot help but parasite the relation between God and humanity that he mediates. The angel sustains himself - he is and remains what he is — only by drawing off a portion of God's Word for himself. As third, he is essential to the system of communication; without him, God and humanity could communicate successfully only on condition that there be no relation between them at all, i.e., that they be immediately the same. Since, of course, they are not the same, the system can function only by including the angelic third. But by the same token, the inclusion of the third necessarily introduces noise into the system. Humanity never receives the pure and unadulterated Word of God, or at minimum can never be certain that it does, precisely because the angel is something. The channel of communication is never perfectly clear. The angel, insofar as he appears at all, then, appears as a third that must be excluded for the sake of the purity of the Word. The angel is thus almost the very definition of the parasite that Serres has been at pains to describe: the necessarily included and excluded third.

But we cannot localize the role of parasite so simply and straightforwardly in the angel. We could in fact equally well isolate God as the parasite in the system. Without the possibility of manifestation, God could not enter into any relation at all, and thus could not be what he most essentially is. God ceaselessly skims his own being as ultimate information source from the work of the angels, without whose mediating activity there could be no information in the first place. He is, then, a parasite in the sense that the squire from La Fontaine's fable was a parasite, as the absolute master of surplus value who claims for himself a portion of all the system's production. And one could equally well isolate humanity as the parasite in the system. Humanity would 
obviously be a parasite in the sense of the hare in the garden. In a paradigm case, the archangel Gabriel appears to Mary announcing a gift for which she could never hope to exchange anything of comparable value. Like God and the angels, humanity is what it is only by parasiting the other elements of the system. Parasitism and its characteristic relation of inequality, then, characterize the system as a whole and each of its parts. Each element ceaselessly profits from the work of the others. And this disequilibrium is not an aberration from the norm; without it there would be no system at all. From this perspective, the parasite is not at all a third to be excluded or even to be grudgingly included, but rather the very origin and principle of the system itself.

The parasite, then, like Kantian respect, is originary. It gives each element of the system to itself as different from itself, in a disequilibrium that is the condition for the meaningfulness of its world. In Kant, this originary disequilibrium between the sensible and intelligible sides of practical reason opens the subject out onto a meaningful moral world. It is this disequilibrium that makes our practical worlds characteristically human: without it, we would live the non-moral lives of gods or of beasts. In Serres's example from Angels, we can also see how each element of the system is what it is through its difference from itself. God can be God only in a world where his being is communicated by the angels. God in equilibrium, in other words, cannot be God. Likewise, human beings are human beings not in themselves, but through their openness to the Word of God. Originary disequilibrium is figured by the angels, who in order to mediate the relation must be at once spiritual like God and fleshly like us, at once intelligible and sensible. But this disequilibrium, as we have seen, cannot be localized so simply in the angels. God is constitutively oriented toward human beings and toward the sensible 
world in general, just as human beings are constitutively oriented toward the Word. "Orientation can thus be said to be originary, invariable, irreducible. ..."31 It is neither God nor humanity, neither the intelligible nor the sensible, then, that is ontologically basic, but rather their orientation each to the other, which first sets them into the relation that makes of them what they are.

In isolating the irreducible role of orientation, we finally discover the key to a comprehensive Serresian redescription of Kantian respect. From the beginning we have been speaking only of sense. We began with the idea that only a finite rational being, whose subjectivity is extended across the difference between sensibility and intelligibility, could have any experience of the moral imperative. As Hegel has pointed out, both sensibility and intelligibility are gathered together in the word sense: "'Sense' is this wonderful word which is used in two opposite meanings. On the one hand it means the organ of immediate apprehension, but on the other hand we mean by it the sense, the significance, the thought, the universal underlying the thing." 32 For Hegel, of course, the double meaning of the term is no accident, but rather articulates something essential in our experience of the world. Kant, we might say, both sees and does not see the inseparability of these two senses of sense. On the one hand, moral worth seems to depend on the rigorous separation between the intelligible law and the sensible inclinations. But on the other hand, Kant cannot avoid bringing the two senses together in the a priori feeling of respect: without the painful feeling that accompanies the thwarting of our sensuous inclinations, we would never become aware of the law as source of moral obligation. With the help of Serres's concepts of noise and the parasite, we arrive at the conclusion that these two senses of sense are gathered together in being 
oriented to each other. This orientation or directedness constitutes a third sense of sense, which is captured well in the French sens. ${ }^{33}$ Just as for Serres the channel of communication is prior to the information source and the point of destination that it connects, so the third, directional sense of sense is more originary than the sensible and the intelligible senses. If our sensible natures were not oriented always already toward the intelligible, we could never experience the necessitation or command that is essential to the phenomenon of morality. Conversely, if the intelligible were not oriented toward sensibility, as the intelligible of the sensible, then we would never experience the law as imperative for us. The two senses of sense are necessarily mediated by a third sense, which is indispensable and yet unthinkable strictly in terms of the other two. Respect, then, just is the happening of the third sense of sense, the necessarily included and excluded third that is always already first.

\footnotetext{
${ }^{1}$ Feeling, for Kant, is one of the two species of the genus sensibility. Immanuel Kant, The Metaphysics of Morals, trans. and ed. Mary Gregor (Cambridge: Cambridge University Press, 1996), 12 [Ak: 6:212]. Hereafter $M M$.

${ }^{2}$ Immanuel Kant, Groundwork for the Metaphysics of Morals, ed. and trans. Allen W. Wood (New Haven: Yale University Press, 2002), 30 [Ak. 4:413]. Hereafter GMM.

${ }^{3}$ Immanuel Kant, Critique of Practical Reason, trans. Lewis White Beck (Indianapolis:Bobbs-Merrill, 1956), 74 [Ak. 5:71]. Hereafter $C P r R$.

${ }^{4}$ Ibid., 24 [Ak. 5:25].

${ }^{5}$ Ibid., 75 [Ak. 5:72].

${ }^{6}$ Kant, $G M M, 14$ [4:398].

${ }^{7}$ Lewis White Beck, A Commentary on Kant's Critique of Practical Reason (Chicago: University of Chicago Press, 1960), 221-2.

${ }^{8}$ Kant, $\operatorname{CPr} R, 81$ [Ak: 5:78].

${ }^{9}$ Ibid., 79 [Ak. 5:76].

${ }^{10}$ In respect, I am also revealed to myself as a moral person with a dignity that I must not violate. The relation of the moral law to the dignity of persons is captured especially well in the second formula of the categorical imperative from the Groundwork: "Act so that you use humanity, as much in your own person as in the person of every other, always at the same time as an end and never merely as a means." Kant, GMM, 46-7 [Ak. 4:429].

${ }^{11}$ Kant, $M M, 210$ [Ak. 6:464].

${ }^{12}$ Kant, $C P r R, 76$ [Ak. 5:73].
} 
${ }^{13}$ Ibid., 78 [Ak. 5:76].

${ }^{14}$ Michel Serres, Hermes: Literature, Science, Philosophy, ed. Josué V. Harari and David F. Bell (Baltimore : The Johns Hopkins University Press, 1982), 66. Hereafter Hermes.

${ }^{15}$ In French, the excluded middle is called le tiers exclu, the excluded third.

${ }^{16}$ Michel Serres, The Parasite, trans. Lawrence R. Schehr (Baltimore: The Johns Hopkins University Press, 1982), 12. Hereafter Parasite.

${ }^{17}$ Kant, $G M M, 43$ [Ak. 4:426].

${ }^{18}$ Kant, $C P r R, 32-3$ [Ak. 5:32-3].

${ }^{19}$ Michel Serres, Genesis, tr. Geneviève James and James Nielson (Ann Arbor: University of Michigan Press, 1995), 112.

${ }^{20}$ David F. Bell, “Le Parasite,” MLN 96, no. 4 (May, 1981) : 886.

${ }_{22}^{21}$ Serres, Parasite, 86.

${ }^{22}$ Ibid.

${ }^{23}$ Ibid., 12.

${ }^{24}$ Ibid., 78-9.

${ }^{25}$ Ibid., 91.

${ }^{26}$ Ibid., 93.

${ }^{27}$ Ibid., 89.

${ }^{28}$ Ibid., 12.

${ }^{29}$ Ibid., 13.

${ }^{30}$ Michel Serres, Angels: A Modern Myth, trans. Francis Cowper (Paris: Flammarion, 1995), 99-113.

${ }^{31}$ Michel Serres, The Troubadour of Knowledge, trans. Sheila Faria Glaser with William Paulson (Ann Arbor: University of Michigan Press, 1997), 15.

${ }^{32}$ G.W.F. Hegel, Hegel's Aesthetics: Lectures on Fine Art, Vol. I, trans. T.M. Knox (Oxford: Oxford University Press, 1975), 128-9.

${ }^{33}$ Cf. Jean-Luc Nancy, The Sense of the World, trans. Jeffrey Librett (Minneapolis: University of Minnesota Press, 1997), 12. "Although the etymology of the word sense is not clear, one constant is that the word is attached to a semantic family in which one finds, first of all, in Irish, Gothic, or High German, the values of movement, oriented displacement, voyage, 'tending toward."' 